NASA Technical Memorandum 100418

\title{
The NASA Integrated Test Facility and Its Impact on Flight Research
}

D.A. Mackall, M.D. Pickett, L.J. Schilling, and C.A. Wagner

(NASA-TH-100418) THE NASA INTEGRATED TEST

FACILITY AND ITS IMPACT ON FLIGHT EESEARCH

(NASA) $16 \mathrm{p}$
CSCL $14 \mathrm{~B}$
N $88-21177$

Unclas

0137315

G3/09 0137315


NASA Technical Memorandum 100418

\section{The NASA Integrated Test Facility and Its Impact on Flight Research}

D.A. Mackall, M.D. Pickett, L.J. Schilling, and C.A. Wagner

Ames Research Center, Dryden Flight Research Facility, Edwards, California

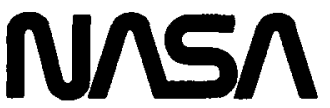

National Aeronautics and

Space Administration

Ames Research Center

Dryden Flight Research Facility

Edwards, California 93523.5000 


\title{
THE NASA INTEGRATED TEST FACILITY AND ITS IMPACT ON FLIGHT RESEARCH
}

\author{
D.A. Mackall, ${ }^{*}$ M.D. Pickett ${ }^{\dagger}$ L.J. Schilling, ${ }^{\ddagger}$ and C.A. Wagner ${ }^{\S}$ \\ NASA Ames Research Center \\ Dryden Flight Research Facility \\ Edwards, California
}

\begin{abstract}
The Integrated Test Facility (ITF), being built at NASA Ames-Dryden Flight Research Facility, will provide new test capabilities for emerging research aircraft. An overview of the ITF and the challenges being addressed by this unique facility are outlined in this paper. The current ITF capabilities, being developed with the X-29 Forward Swept Wing Program, are discussed along with future ITF activities.

\section{Nomenclature}

$\begin{array}{ll}\text { CAD } & \text { computer aided design } \\ \text { FCC } & \text { flight control computers } \\ \text { ITF } & \text { integrated test facility } \\ \text { KASDT } & \text { knowledge aided system design tool } \\ \text { LVDT } & \text { linear variable differential transformer } \\ \text { PCM } & \text { pulse code modulation } \\ \text { pSi } & \text { pounds per square inch } \\ \text { RAV } & \text { remotely augmented vehicles } \\ \text { RCD } & \text { remotely computed displays } \\ \text { RCV } & \text { remotely computed vehicles } \\ \text { RPRV } & \text { remotely piloted research vehicles } \\ \text { SID } & \text { simulation interface device } \\ \text { STIL } & \text { system test interface language } \\ \text { STR } & \text { system test report }\end{array}$
\end{abstract}

\section{Introduction}

The goal of the Integrated Test Facility (ITF) is to provide ground test capabilities that allow safe and efficient testing of advanced, integrated research aircraft. Characterized by the integration of flight control, propulsion, structures, and aerodynamics, these integrated research aircraft rely on embedded digital control systems. The ITF addresses the qualification needs of today's integrated systems aircraft. ${ }^{1}$

*ITF Lead Engineer

'Senior Simulation Engineer

${ }^{\ddagger}$ Lead Simulation Engineer

$\$$ Lead Electromechanical Engineer
The ITF will reduce flight test risk by minimizing the difference between the flight and ground test environments. This ground test environment is provided by interfacing the real-time flight simulation with the actual aircraft through a simulation interface device. Other challenges being addressed by the ITF include increasing test efficiency by automating the test process; the collection and management of test data; and information management of the aircraft systems and ground-based simulations (the management of information describing complex, interrelated systems).

An overview of the features of the ITF building, the challenges facing the facility, and the progress made to date in addressing these challenges are provided in this paper. Future development activities for the ITF also are summarized.

\section{Overview of the Integrated Test Facility}

In the first section of this paper, we give an overview of the physical features of the ITF building and describe the major functions provided by the ITF. The three major functions addressed are aircraft simulation, the remotely computed vehicle system, and aircraft maintenance. These functions are currently performed at Ames-Dryden, but their capabilities will be enhanced when they are moved into the ITF.

\section{Building Features}

A cutaway view of the ITF is shown in Fig. 1. The facility contains hangar (test bay) space for six fightersize aircraft, broken into three separate areas. Each area can be configured to support classified projects. The aircraft technicians and maintenance staff are on the first floor of the central section. The engineering staff is in the front section of the building, with ample room allowed for visiting contractors. The second floor of the center section of the building houses the flight simulation systems, placing them in proximity to all six test bays. This allows the required short connection distances between the aircraft and simulation systems needed for closed-loop simulation with the flight vehicle. 
Aircraft services, such as electrical power, hydraulic supplies, and cooling air, are provided to support aircraft-in-the-loop simulations. All the aircraft services can be monitored in real time when performing tests with the aircraft (Fig. 2).

The electrical power provided includes $277 / 480 \mathrm{~V}$ and $120 / 208 \mathrm{~V}$, three phase, $60-\mathrm{Hz}$ power; $120 / 208 \mathrm{~V}$, three phase, $400-\mathrm{Hz}$ power; and $28 \mathrm{~V}$ dc power.

The hydraulics systems for the six test bays are independent, allowing for different pressures and fluids to be used. The initial hydraulics system is a three-pump system providing 35 gallons per minute ( $\mathrm{gal} / \mathrm{min}$ ) at 5000 pounds per square inch ( $\mathrm{psi}$ ) pressure for each of the three pumps. This provides a total of $105 \mathrm{gal} / \mathrm{min}$ at $5000 \mathrm{psi}$. The flow per pump can be increased to $50 \mathrm{gal} / \mathrm{min}$ at a pressure of $3500 \mathrm{psi}$.

The aircraft cooling system is designed to provide each test bay with 4000 cubic feet per minute $\left(\mathrm{ft}^{3} / \mathrm{min}\right)$ of air flow. Exit air temperature is $40^{\circ} \mathrm{F}$, provided through two 14-inch supply ducts.

\section{Aircraft Simulation}

The ITF will support flight simulation systems at NASA Ames-Dryden. The simulation systems will bring to the ITF 30 years of real time simulation experience and expertise. Simulations are important engineering tools used through all phases of flight research. The simulations are used to perform various tests: time history, frequency response, redundancy management, failure modes and effects testing, and pilot evaluation.

To augment these diverse uses, the ITF will support multiple simulation configurations for a given project with varying levels of aircraft hardware included. These simulations run the full spectrum from simple batch versions, which use only the computer and a user terminal, to complex aircraft-in-the-loop versions. This allows the project team to easily select the level of hardware needed to support a session's activities. This flexibility permits quick comparisons between software models and flight hardware. It also allows a proposed modification to be tested in the ITF before being installed on the aircraft.

High-fidelity modeling of the aircraft systems and environment is of key importance in the ITF. This highfidelity modeling provides aircraft hardware with a realistic flight environment. This task becomes increasingly important and demanding as aircraft systems become interdependent.

A major goal of the ITF is to provide a flexible, capable, engineering environment responsive to the user's needs. The ITF simulation interfaces give users fingertip control of the simulation. The simulations can be controlled by buttons and switches in the cockpit, or from a menu of display pages on a cathode ray tube (CRT), or the entire control mechanism can be run automatically from the workstation. The workstations generate simulation script files to automate the process of running tests. They provide a high-level simulation interface, bypassing the need to know the simulation commands to enter at the CRT display page.

\section{Remotely Computed Vehicles}

The ITF will have the ability to operate remotely computed vehicles (RCVs). As with the simulation systems, Ames-Dryden has a great deal of experience with RCV systems which will be transferred to the ITF.

RCVs will use telemetry uplink and downlink systems and ground-based computers in the ITF. The ground-based computers are named the Control Law computer and the Pulse Code Modulation (PCM) computer. The Control Law computer is FORTRAN programmable and is used to augment the onboard control systems. The Control Law computer uses downlink data to generate aircraft commands. The PCM computer shares memory with the Control Law computer and is the interface between it and the telemetry stream. The PCM computer converts between scaled integers used in the telemetry stream and engineering units used by the Control Law computer.

Currently, a computer identical to the Control Law computer is paired with each simulation computer for verification and validation of the RCV ground-based software. The simulations are designed to interface to this computer in the same maneuver as the PCM computer. Timing relationships are preserved to accurately model the real system. The relationship between the Control Law computer and the PCM computer in the $\mathrm{RCV}$ laboratory and in the simulation lab is shown in Fig. 3.

The three types of RCVs supported by the ITF are described as follows and shown in Fig. 4.

1. Remotely piloted research vehicles (RPRVs) are flown from a ground-based cockpit. The vehicle's control laws are coded in FORTRAN and executed in the Control Law computer. RPRVs that have been flown at Ames-Dryden range from the subscale highly manueverable aircraft technology (HiMAT) vehicle ${ }^{2}$ to the joint FAA/NASA Controlled Impact Demonstration using a Boeing $720 .^{3}$

2. Remotely augmented vehicles (RAVs) use the ground computer to augment the onboard control system. This ability can be used to test alternate control laws, insert sophisticated autopilots to fly precise research maneuvers, or to generate pulses or frequency sweeps for data analysis. The $\mathrm{X}-29$ airplane is an example of a current research aircraft using RAV operation.

3. Remotely computed displays (RCDs) help to guide the pilot in flying a precise manuever. The Control Law computer uses downlinked data to calculate the fly-to signals sent to the aircraft display in- 
struments. An example of a current research project using RCD operation is the F-18 aircraft high angleof-attack project.

Once the RCV laboratory is moved to the ITF, its design will be improved by removing the need for the duplicate Control Law computer. In the ITF, one Control Law computer will interface to both the simulation and PCM computers. The same computer will be used to test and execute the control law code. This will eliminate the overhead associated with strict configuration control between duplicate computers.

\section{Aircraft Maintenance Facilities}

Routine aircraft maintenance required by the flight research vehicle is also provided within the ITF. This includes the preflight and postflight checks of instrumentation systems and the servicing of hydraulics systems. The first floor of the central section provides shop space for the instrumentation, avionics, and mechanical system technicians. Space is provided for nongovernment technicians working on flight test programs.

\section{Challenges Facing the ITF}

In this section, we address the challenges facing development of the ITF and the steps being taken to meet these challenges. The approach is to develop the capabilities while the building is being constructed in order to provide a functional facility when construction is completed in early 1990. Current research vehicles such as the X-29 forward swept wing aircraft are being used to demonstrate these capabilities.

\section{Routine Setup of Aircraft-in-the-Loop Flight Simulation}

A primary function of the ITF is to facilitate the development and test of research aircraft using aircraft-in-the-loop simulations. Such simulations have been constructed at Ames-Dryden, with HiMAT being an example. These simulations have required a great deal of time and effort to build and were very project specific.

For the ITF to be successful, development of aircraftin-the-loop simulations will need to take place quickly and efficiently. Once the development effort is complete, the simulation system will need to be easily connected and disconnected from the aircraft being tested. Because Ames-Dryden flies many unique research vehicles, this interface will need to be flexible. The interface will have to support vehicles that range from commercial planes like the Boeing 720 aircraft to fighters like the F-18 aircraft.

The general requirements for interfacing between the simulation and the aircraft systems are described in the following paragraphs.
The first requirement is a real time analog interface to the aircraft flight control, avionics, sensors, and actuators. This interface is necessary to provide the aircraft systems with an environment that is as realistic of flight as possible and to allow the simulation systems to monitor the aircraft systems being tested.

The second requirement is protection of the aircraft electronic systems from electrical overloads. The same aircraft that are actively flying research missions will be used for ground testing in the ITF. Thus care must be taken to prevent possible damage to aircraft systems.

The third requirement of the interface is the capability to interact with the aircraft systems without inducing undesired side effects such as large ground loop currents. The interface must not induce time delays or other effects that will alter the dynamics of the aircraft's response.

The fourth requirement is the ability to support remote, electronic configuration of the interface. This requirement is generated by the need to use automated testing. In order to automate the testing process, the simulation computer will need to control the setup of gains and biases for the interface.

The challenge of providing a flexible analog interface between the simulation computers and the research aircraft is being met by the simulation interface device (SID). A SID prototype is under development to demonstrate the general requirements outlined in the foregoing paragraphs. The first application of the SID is an aircraft-in-the-loop simulation with the $\mathrm{X}-29$ aircraft. The X-29 application imposes project specific requirements upon the SID which will also be demonstrated.

The specific requirements of the $\mathrm{X}-29$ aircraft for the SID include (1) real time six degree of freedom simulation with the actual flight aircraft, (2) summation of the aircraft's sensor outputs with the values coming from the simulation, and (3) the ability to dynamically change gains in the SID paths to validate flight control gain margins. The test configuration with the $\mathrm{X}-29$ aircraft and the relationship of the SID to the other systems are shown in Fig. 2.

The generic SID provides unique real time analog and discrete aircraft interfaces by means of electronic card slots containing aircraft specific circuitry. Each SID rack provides 128 analog and 16 discrete card slots. The design of each card may be generic in some cases. In other cases, it is unique to the aircraft systems which must be connected. In the case of the X-29 aircraft, the SID includes cards that sum aircraft sensor values with values from the simulation (Fig. 5), cards to substitute values for attitude sensors using synchro outputs, and cards to demodulate the linear variable differential transformer (LVDT) outputs of the actuators into direct current (dc) voltages. 
The summation of the aircraft sensors to the simulation's values allows the flight control system to detect the aerodynamic response of the aircraft and the structual response of the aircraft as measured by the onboard sensors. This is essential for performing structural resonance tests in which the aircraft's sensor values are multiplied by a gain until a structural resonance is detected. The gain determines the amount of margin available for the control loop.

Each of the card slots can be programmed with up to eight specific values to support automated testing. In the case of the card that sums aircraft values with simulation values, the card can be remotely configured to change the gain in either path, to directly connect the aircraft sensors to the vehicle without summing in the simulation values, and to adjust output signal biases.

Overvoltage protection must be designed to match the type of signal which is received or sent to the aircraft. As a result, the overvoltage protection is a generic feature of the SID but is designed to the specific requirements of each research aircraft. Each of the three types of cards for the X-29 aircraft, the summation card, the synchro card, and the LVDT card, has its unique overvoltage protection circuitry.

Because significant ground potential differences exist between the simulation computer and the aircraft (which is electrically connected to a supporting hydraulic system, a power source, and other services), it is frequently difficult to accurately transfer low-voltage signals back and forth. The SID addresses this problem by providing only nonohmic connections to the aircraft. Depending on the signal type, these connections use $\mathrm{dc}$ isolation amplifiers, transformers, and relays as appropriate. These isolation devices are included on each card.

The simulation interface device provides the flexibility needed to quickly connect the flight simulation systems to the variety of research aircraft flown at AmesDryden. It does so while providing real time interfaces needed for flight simulation, protecting the aircraft electronics, and supporting remote setup and test automation. The SID is an essential part of the ITF, providing the aircraft electronics with a test environment surpassed only by actual flight.

\section{Increasing Ground Test Efficiency}

There are two main areas of ground testing that require increased efficiency. First is the ground testing to verify system and software changes made to the research vehicle. These changes typically occur on a monthly basis and require large amounts of testing. Second is the ground testing performed between flight test sorties. This addresses preflight and postflight checks of instrumentation, and ground test of the specific research experiment being flown. This testing is short in duration but occurs frequently, usually daily.
Software and system verification is the first area to be addressed in the ITF because of the high costs and time to complete this test. The flight critical nature of the software, usually flight control software, also requires that steps be taken to improve the process of ground testing in this area in order to minimize flight test risk. Protection against test conductor errors and the ability to reproduce test setup conditions need to be improved. The rate at which tests can be started and carried out will have to be greatly increased because of the volume of tests required in today's highly integrated aircraft.

The number of flight control software changes that occur on a typical flight program runs into the hundreds. The advanced fighter technology integrated (AFTI) F-16 program processed 240 change requests during the digital flight control system flight test phase, the majority being software changes. ${ }^{4}$ Development of the A310 slat and flap control system saw over 700 software change requests. ${ }^{5}$ Testing must address each change individually as well as verify that functions which were not changed still work correctly.

The challenge is to increase ground test efficiency by automating the test process used in the verification and validation of flight critical software systems. The X-29 project was selected to demonstrate the first phase of the automated testing process designed to meet this challenge.

The X-29 test chosen for demonstration was an openloop frequency response. This test was selected because it is an actual application, being part of the verification and validation process of new blocks of flight control software and requires nearly 50 test runs. The test was performed on the real time hardware-in-the-loop simulation. This simulation contains flight control computers (FCCs) identical to those in the airplane.

An engineering workstation was added to the simulation system to facilitate the automated test (Fig. 2). Public domain software and commercially available hardware and software packages were used in the workstation system wherever practical. The workstation provided several capabilities summarized in the following paragraphs.

One of the key elements of the automated test system is the data base management system it provides. The data base management system provides a user interface for inputting test data and a method for extracting data to set up the initial conditions of the test run. It also archives the test results data files. These initial conditions and results files can be accessed by the system for comparing data and producing reports. The management system can query the data base and list test results that meet stated criteria.

A communication link between the simulation system and the workstation was also an essential capa- 
bility that was added. The current link uses public domain software and an RS-232 connection. This link will be replaced by one with a higher data transmission rate. Ethernet (Xerox Corp., Stamford, Connecticut) and MIL-STD-1553 are two busses being considered.

Another capability of the automated test system is the data analysis tools it provides. These tools are used to analyze the data collected from the test. For the X-29 automated test demonstration, a public domain data analysis software package was selected to generate phase, gain, and coherence data from the input and output data recorded during the open-loop frequency response test.

A final capability of the automated test system is the ability to make graphs and reports for evaluation and documentation of the test. The data produced by the data analysis tool are presented to the test conductor on a graphic monitor and also output on the laser printer. The report generation capability of the workstation outputs system test report (STR) forms. Segments of these forms are automatically filled in from data extracted from the data base. Written descriptions of the test are filled in by the test conductor.

The X-29 simulation software required modification to support the automatic testing. These modifications were made in a generic manner for easy incorporation into other simulations. The automated testing simulation software was designed to be flexible enough to handle all anticipated flight control system tests.

Figure 6 shows the flow of control and data through the automated testing system used for the X-29 demonstration. The test conductor starts the process by selecting a test from the data base menu. The data base management handler then executes the system test interface language (STIL) interpreter. This program extracts the information needed for the selected test from the data base and generates a script file of simulation commands.

The resulting script file is then automatically transferred to the simulation computer and the simulation is executed. The simulation follows the script of commands, setting up the initial conditions of the test, and then performs the test while collecting and storing the real time data. During the test, the simulation sends a display to the workstation which can be monitored by the test conductor. The simulation is then stopped, and the test results are automatically sent to the workstation.

Once the data are retrieved by the workstation, the data analysis program is started. The data analysis program runs from script commands and outputs the plots to the test conductor's display terminal and a laser printer. The STR documentation is then generated and printed. The results of the test are archived on the workstation and can be retrieved for comparison against future tests.

This approach to automate the frequency sweep test on the X-29 aircraft was successfully demonstrated. Elements derived from this automated testing demonstration are now being applied to other tests to increase the efficiency of validating new blocks of software for the X-29 airplane. With the inclusion of a high-speed data path between the simulation and workstation, openloop frequency response tests can be run at a rate of up to 15 per $\mathrm{hr}$. This includes all aspects of the test process, such as setup, frequency sweep, data recording, data analysis, and final documentation.

\section{Data Collection and Management}

The collection and management of large amounts of test data is another challenge facing the ITF. A difficult problem occurs in testing complex interrelated aircraft systems when a nonrepeatable failure happens. Often the data needed to resolve the failure is missing, but rerunning the test, with the proper instrumentation, does not reproduce the failure. By recording all possible aircraft and simulation data during a run, the ability to resolve a failure without repeat runs is more likely. The ITF systems will need to collect and record, in real time, data from the simulation, the aircraft digital data busses, the telemetry system, and the ITF services (hydraulic pressure, cooling air temperature). An estimate of the quantity of data to be recorded is shown in table 1 . These data will need to be time tagged to enable time correlation of events that occur during the test.

\section{TABLE 1.-DATA SOURCE AND QUANTITY FOR RECORDING}

\begin{tabular}{lccc}
\hline \hline \multicolumn{1}{c}{ Source } & $\begin{array}{c}\text { Number of } \\
\text { parameters }\end{array}$ & Rate, $\mathrm{Hz}$ & $\begin{array}{c}\text { Total, } \\
\text { sample/sec }\end{array}$ \\
\hline Simulation & 50 & 100 & 5,000 \\
Aircraft & & & \\
$\quad$ Flight control & 300 & 100 & 30,000 \\
$\quad$ Digital busses & - & - & 150,000 \\
Telemetry & 100 & 100 & 10,000 \\
ITF services & 20 & 10 & 200 \\
\hline Total & & & 195,200 \\
\hline \hline
\end{tabular}

The method of collecting and storing the large amounts of data needed for aircraft-in-the-loop testing has yet to be determined. Some of the possibilities include (1) high-speed disk drives, (2) large banks of memory that can be dumped to disk after the run, (3) use of data compression schemes, and (4) a dedicated input-output computer with shared memory to the simulation system. The actual solution will likely be a combination of these approaches. The goal is to record all aircraft and simulation data during a test run. 
A method of managing the test data will be required. The ITF will have data bases for each flight program (Fig. 7). Each data base will contain data from flight test and simulation runs which use varying amounts of hardware-in-the-loop. The management system will need to track the revision levels of the simulations and flight software used in each test run. Revision levels will change with hardware and software modifications. For each data set from a given simulation, many different kinds of tests will be run. For each run, the system will need to track the flight conditions under which each test was performed.

A data base management system will be used to track the data sets. This data base management system will track all of the key parameters mentioned. This system is expected to be an outgrowth of the management system currently in use with the automated test system. The data base management system provides test personnel with the ability to find and compare test runs within minutes. Since the majority of testing is the reverification of a baseline system, comparisons to previous test data are essential.

Extensive real time data recording of all possible aircraft and simulation data, coupled with the data base management of simulation and flight test data will greatly increase test efficiency and help to ensure aircraft flight safety.

\section{Aircraft and Simulation System Information Management}

The increased complexity of research aircraft has caused an overflow of information to flight test personnel, which can no longer be managed by manual techniques. Avionics systems functionality, hardware and software descriptions, and system reliability cannot be tracked and properly assessed using written documentation. Knowledge held by the design team is often lost by the time flight testing begins. Test conductors are often left examining piles of documentation in an attempt to determine proper system operation. This problem is not limited to research aircraft, but is also a major concern for the space station. ${ }^{6}$

For example, an error is likely to pass undetected when the independent test team, meaning independent of the design team, must become knowledgeable about a design by reading stacks of written documentation. This is a time-consuming effort with little chance to interact with the designer. What is needed to create good test plans is easy access to knowledge about the design.

The problem of understanding and documenting the flight research systems is compounded when it must be tied to a ground simulation system for testing. Flight critical control system validation is one example that requires this type of configuration (Fig. 2). Often when something is not working, the question is asked, "Is it the simulation or the control system?" Managing the aircraft and simulation information, that is, the functional, system, hardware, and software descriptions, is essential for accurate and timely testing.

The challenge is to provide a computerized method of documenting complex research systems, showing all the interactions that can take place. This challenge is being met by the use of the knowledge aided system design tool (KASDT). The tool is being developed first to address the computerized management of information on a research flight control system. This information is typically multidisciplinary data and covers a range of aircraft systems. Once the tool is developed to document the more complex and critical aircraft control system, it can then be expanded to include the simulation system data.

The KASDT is using the latest techniques from artificial intelligence and expert systems to provide a hierarchical knowledge base and a set of reasoning functions that describe a flight control system (Fig. 8). The knowledge base consists of three main sections: (1) system descriptions, (2) software descriptions, and (3) hardware descriptions (Fig. 9). Reasoning functions are provided to help the user examine the knowledge base and perform high-level analysis of the system.

The approach used to describe the three sections of the knowledge base varies for each section. The system description contains a functional description of the flight control system using structure design methodologies. ${ }^{7}$ The top-level design for a flight control system is shown in Fig. 10. Circles represent processes, boxes represent external devices (typically hardware), and lines represent data flows. The top portion of the figure shows the knowledge base graph for the processes described. This technique has been popular in the software engineering community. The user graphically builds the system design on the screen while the tool automatically builds the underlying knowledge base. The system knowledge base is linked to the appropriate sections of the hardware and software knowledge bases which describe the actual implementation of a function.

The method used to describe the flight control software is essentially the same as that used for the system description. Structured design techniques are used as before, but the knowledge base created is appropriate for software information. Links to a separate software development system are provided to download the software descriptions without retyping the data. The knowledge base is designed specifically to describe Ada software.

The method for describing the hardware is different from the others because of the variety of hardware devices. Descriptions of aircraft sensors, computers, actuators, pilot displays, and communication devices all require unique descriptions. The aircraft electrical and 
hydraulic systems must also be described. Therefore, the approach is to create a library of such devices that can be graphically connected into a system. This is the same technique used by computer aided design (CAD) systems to design electronic circuit boards.

Reasoning functions provide the users with ways to view and analyze the information. One example of a reasoning function from the software area is the ability to set initial conditions, such as flight control mode and gear position, and have the system determine which software paths are active and the amount of real time being used. This information is then displayed in graphical format showing data flows, processes, and timing.

Once the generic user interface and knowledge base design are completed, the flight control system information can be added. The tool is designed to support the descriptions of any complex digital system, allowing expansion of the information to include the groundbased simulation system.

By providing complete system information in graphical format, with supporting reasoning functions, test engineers will gain the insight required to effectively qualify today's research aircraft.

\section{Concluding Remarks}

The Integrated Test Facility, with its new capabilities, will provide a ground test facility unlike any other. By being able to routinely interface the research aircraft with the flight simulation, the risk of flight re- search will be minimized. Automated testing is increasing test efficiency, allowing more productive flight testing. The ITF brings to the flight research community capabilities needed to ensure our preeminence in aeronautics and provide safe, efficient flight testing.

\section{References}

${ }^{1}$ Mackall, D.A.: Qualification Needs for Advanced Integrated Aircraft. NASA TM-86731, 1985.

${ }^{2}$ Evans, M.B.; and Schilling, L.J.: The Role of Simulation in the Development and Flight Test of the HiMAT Vehicle. NASA TM-84912, 1984.

${ }^{3}$ Kempel, R.W.; and Horton, T.W.: Flight Test Experience and Controlled Impact of a Large, FourEngine, Remotely Piloted Airplane. NASA TM86738, 1985.

4 Joyner, M.L.: AFTI/F-16 Digital Flight Control System Evaluation. AFFTC-TR-83-48, Dec. 1983.

${ }^{5}$ Hills, A.D.: Digital Fly-By-Wire Experience. AGARD Lecture Series 143 on Fault Tolerant Hardware/Software Architecture for Flight Critical Function, Oct. 1985.

${ }^{6}$ Wechsler, D.B.; and Crouse, K.R.: An Approach to Design Knowledge Capture for the Space Shuttle. NASA TM-89272, 1987.

${ }^{7}$ Brock, L.D.; and DeWolf, J.B.: Proposed Requirements for Integrated Avionics Systems. NADC Report 82172-50, July 1983. 


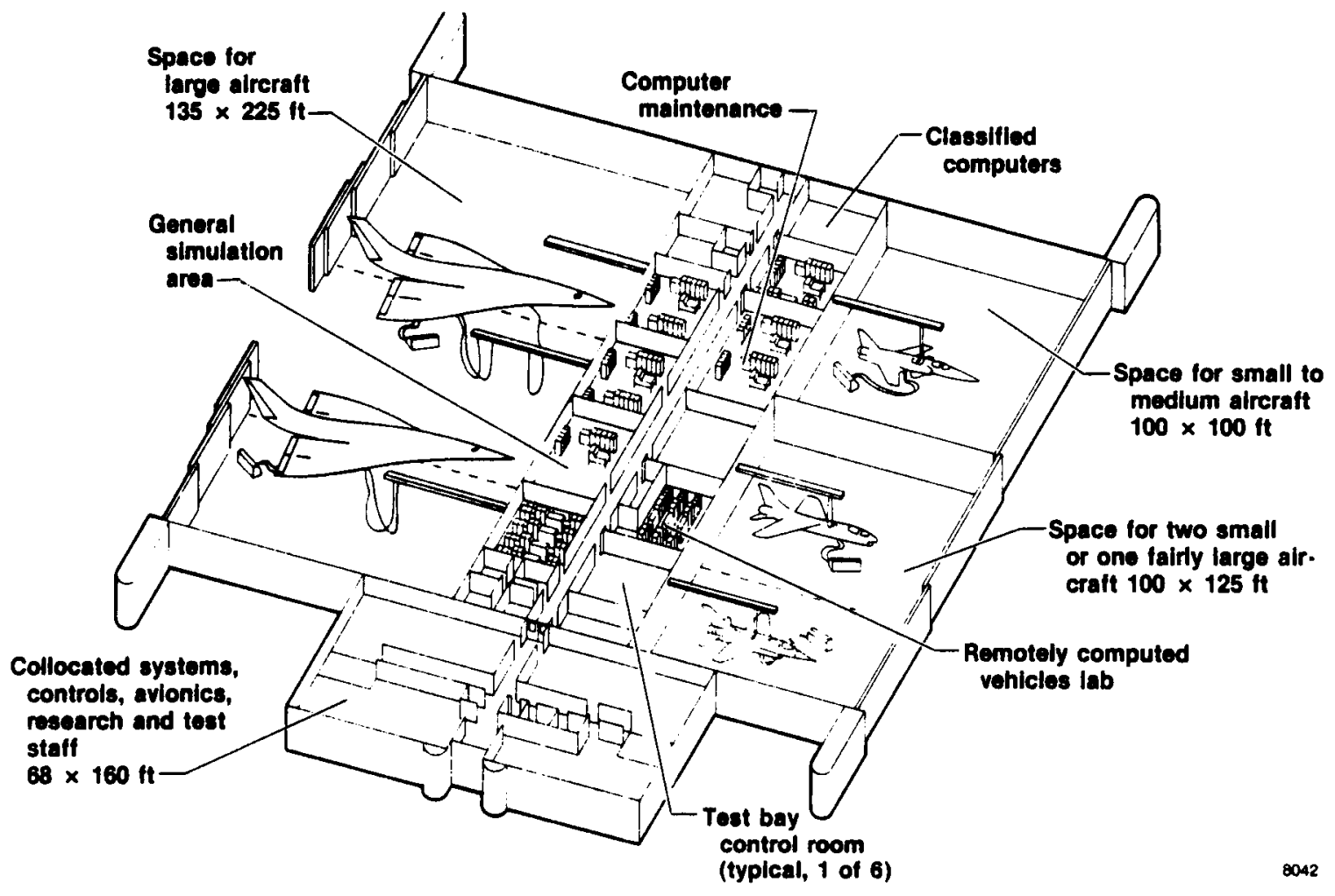

Fig. 1 Overview of the integrated test facility.

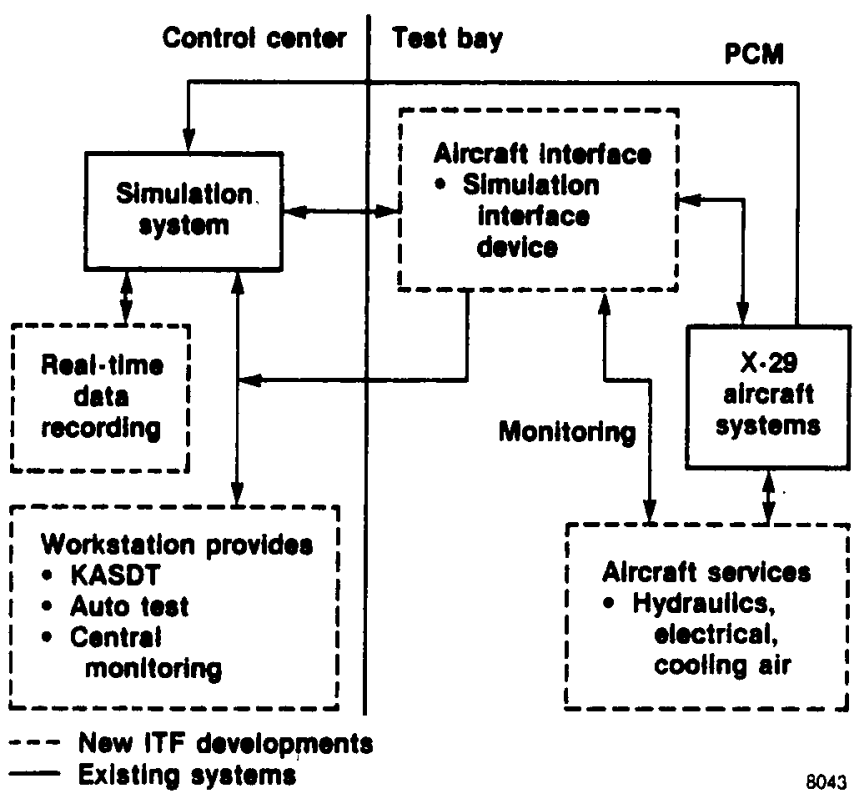

Fig. 2 Overview of ITF test systems. 


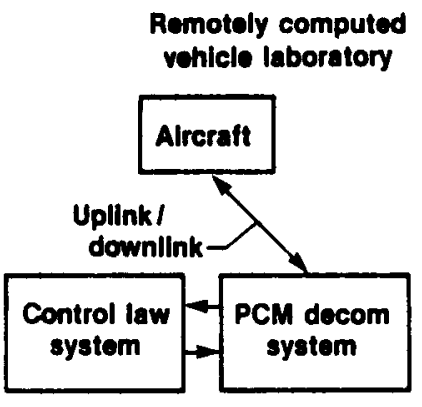

Shared memory interface

Flight test contlguration
Simulation laboratory

Simulation system models the alreralt and PCM system

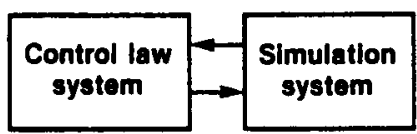

Shared momory interface

Development configuration

Fig. 3 Control law system configurations for flight and development.

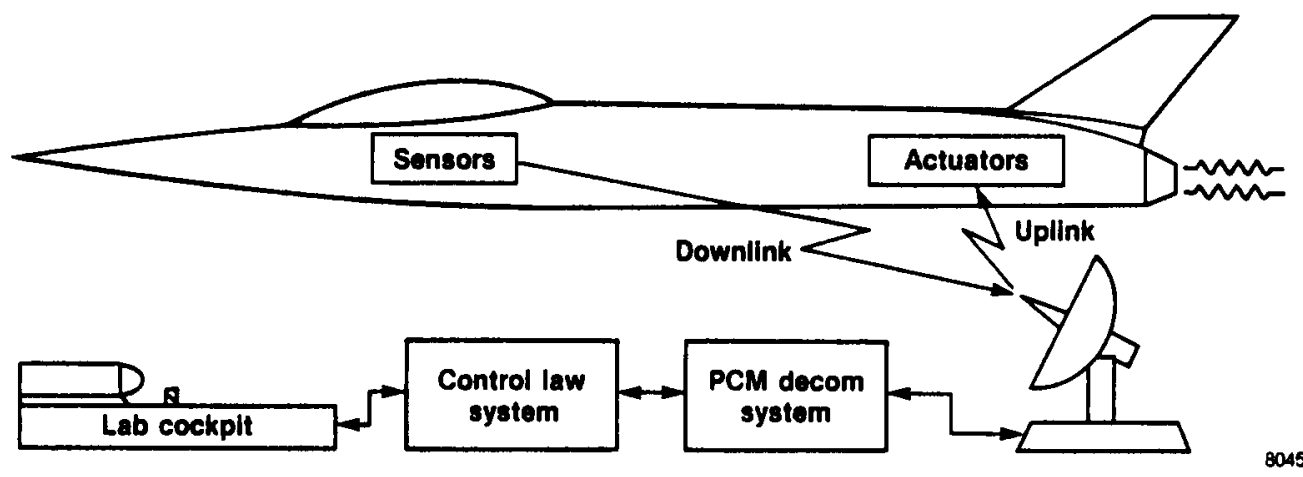

(a) Remotely piloted vehicles.

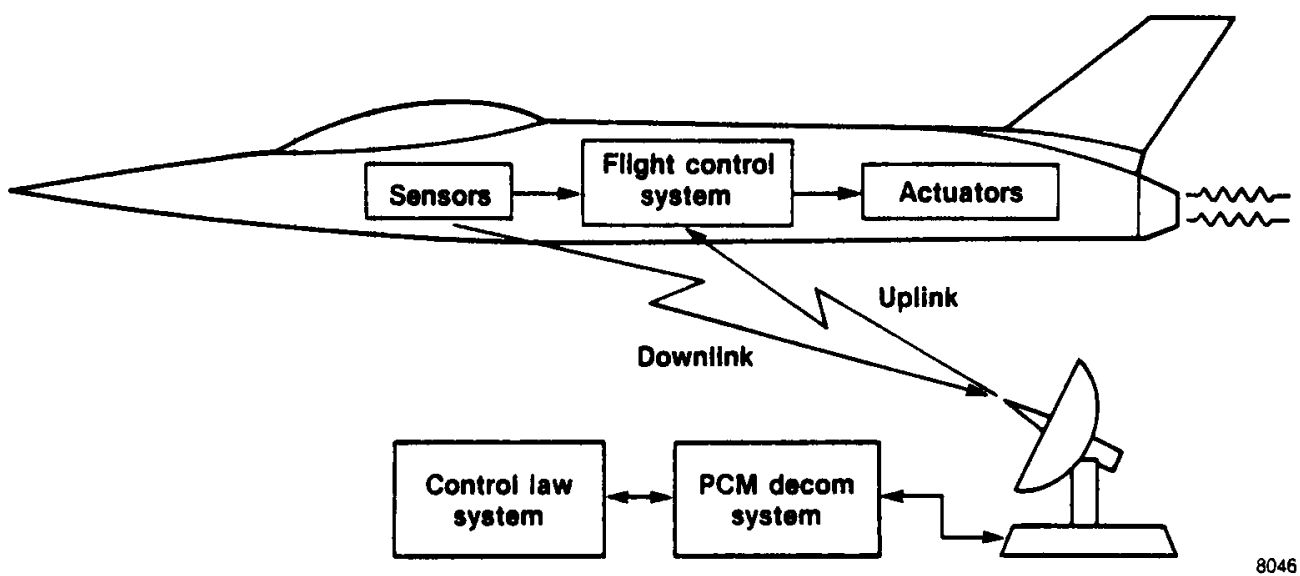

(b) Remotely augmented vehicles.

Fig. \& The three remotely computed vehicle configurations. 


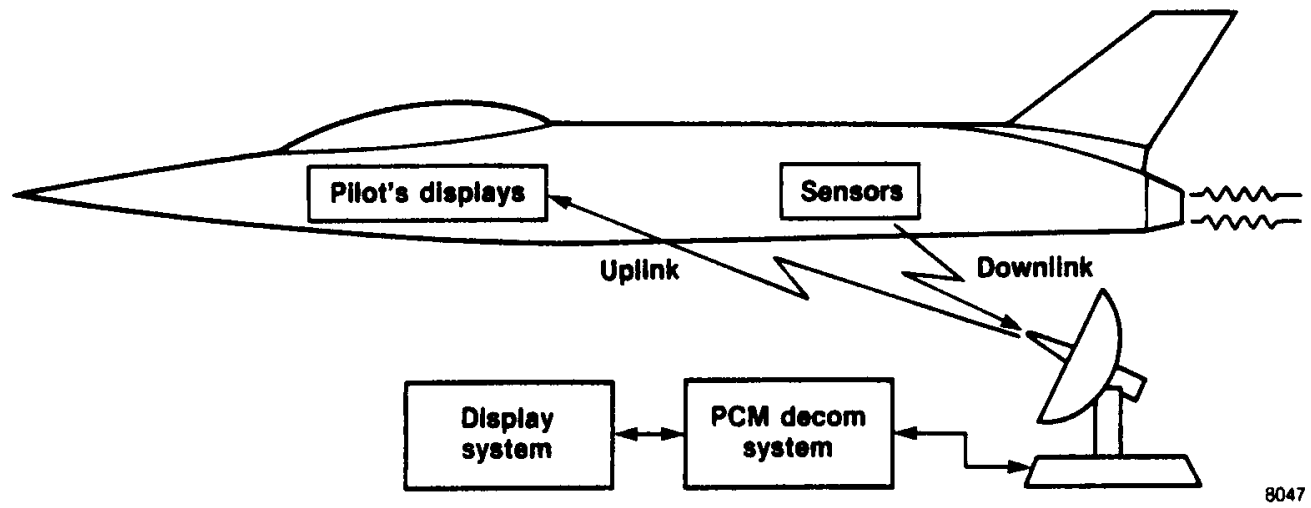

(c) Remotely computed displays.

Fig. \& Concluded.

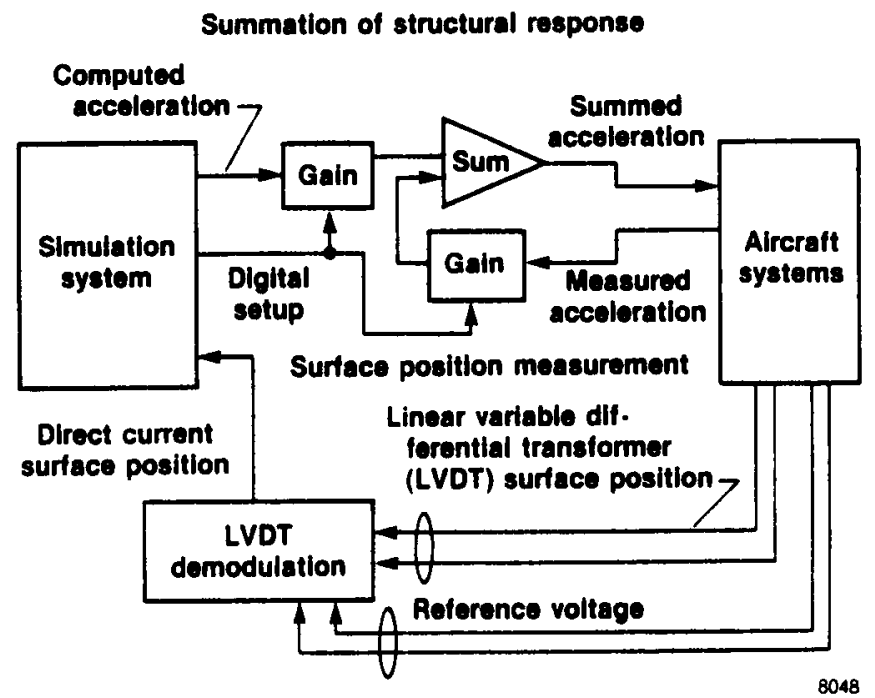

Fig. 5 Typical SID functions. 


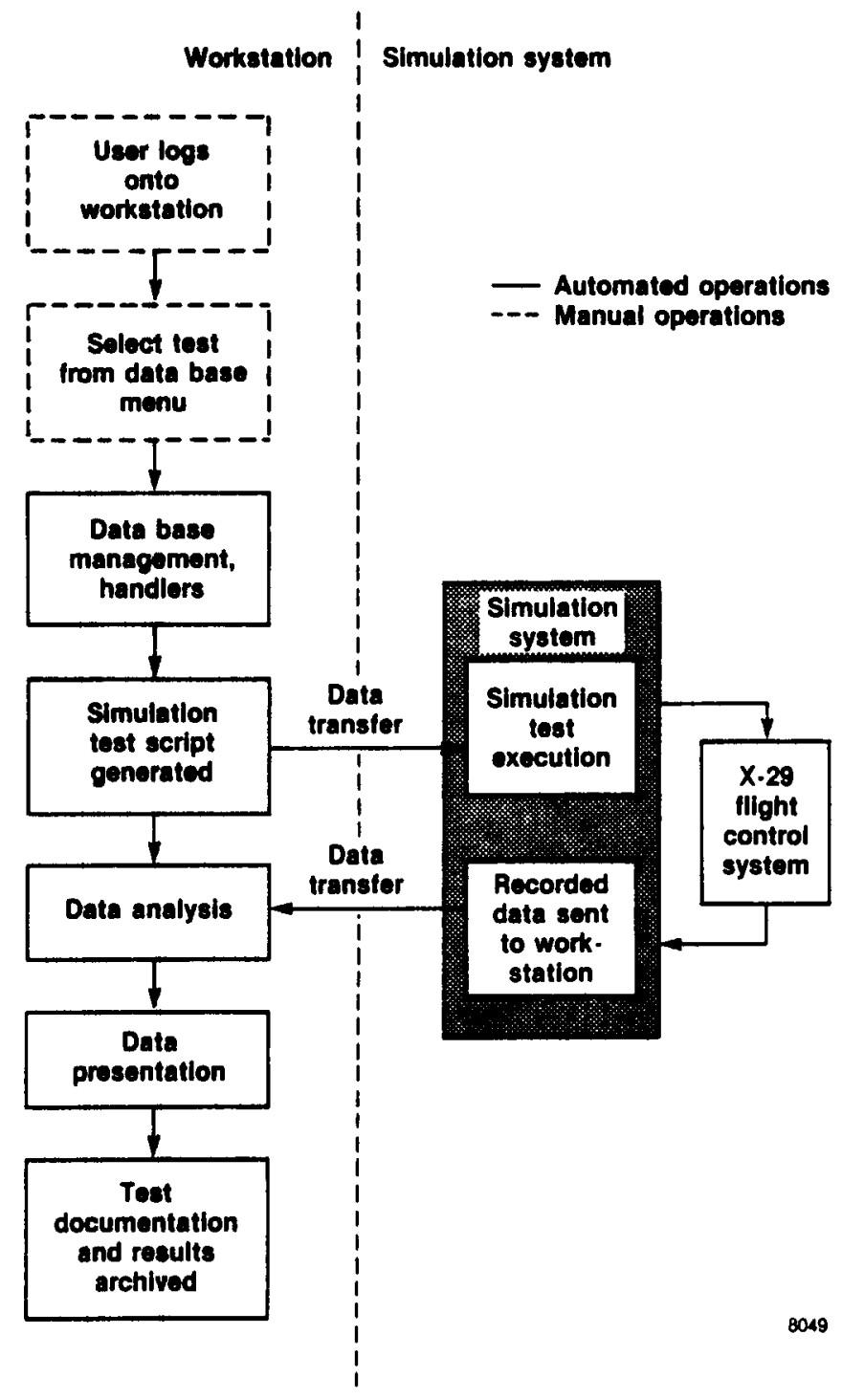

Fig. 6 Automated test system.

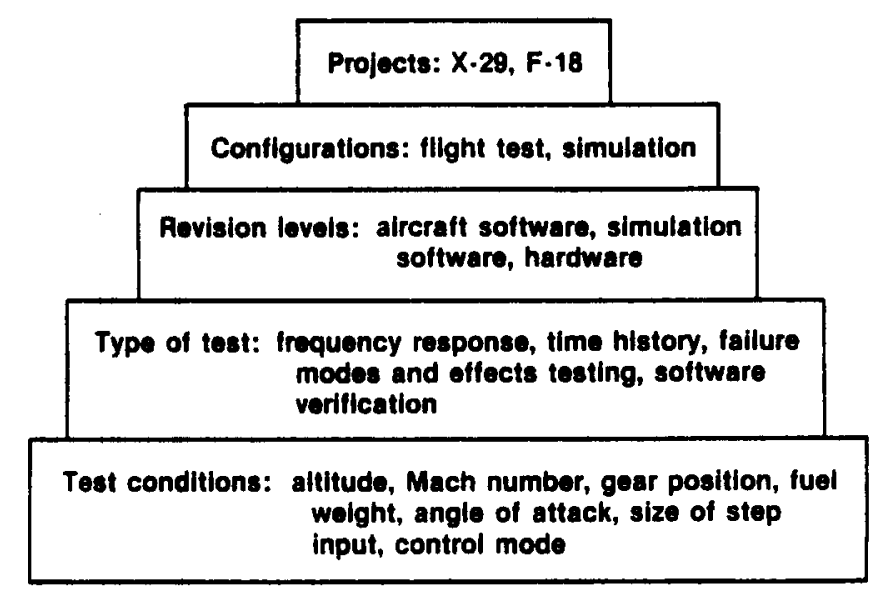

8050

Fig. 7 Five lepels of data base detail. 


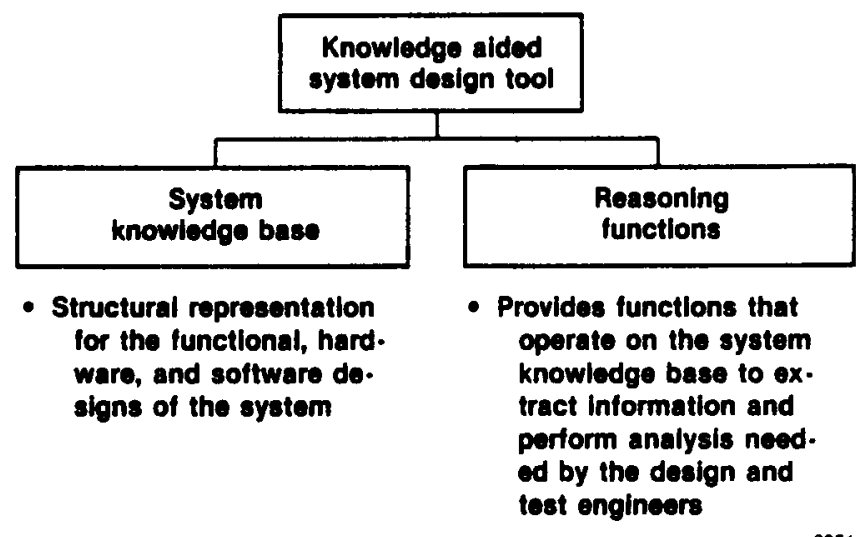

Fig. 8 Structure of tool.

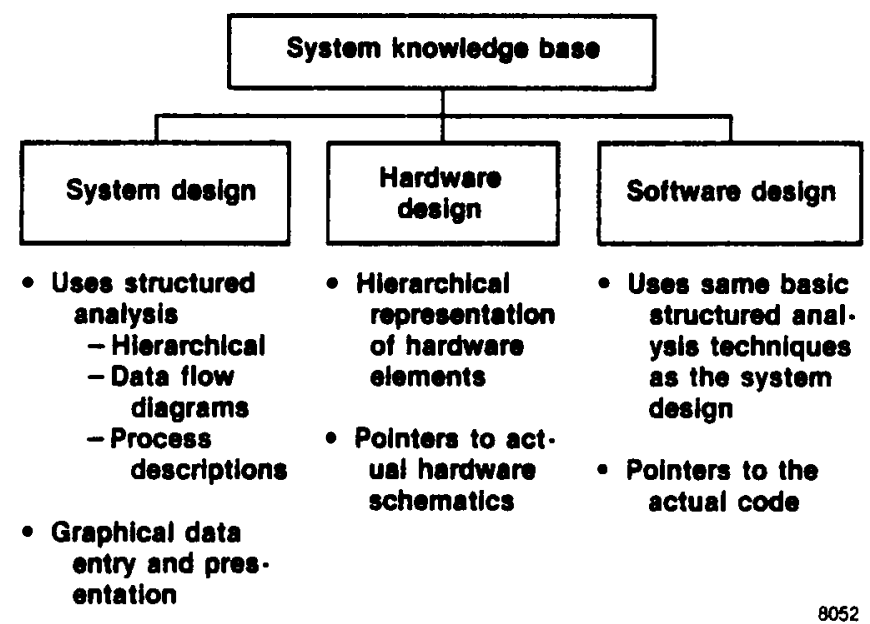

Fig. O System knowledge base. 


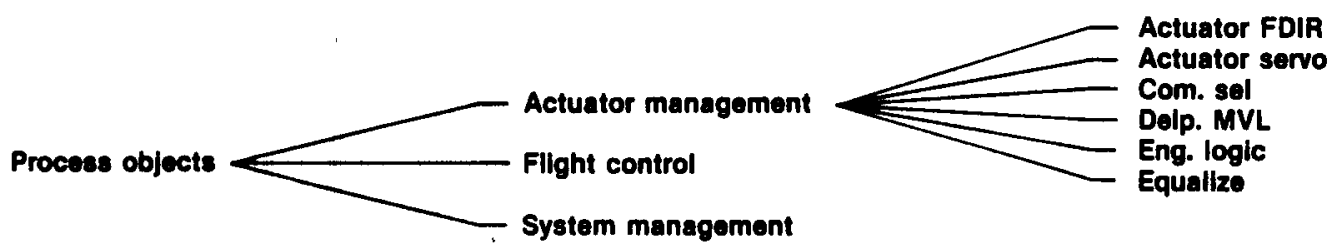

Flight control system top level data flow

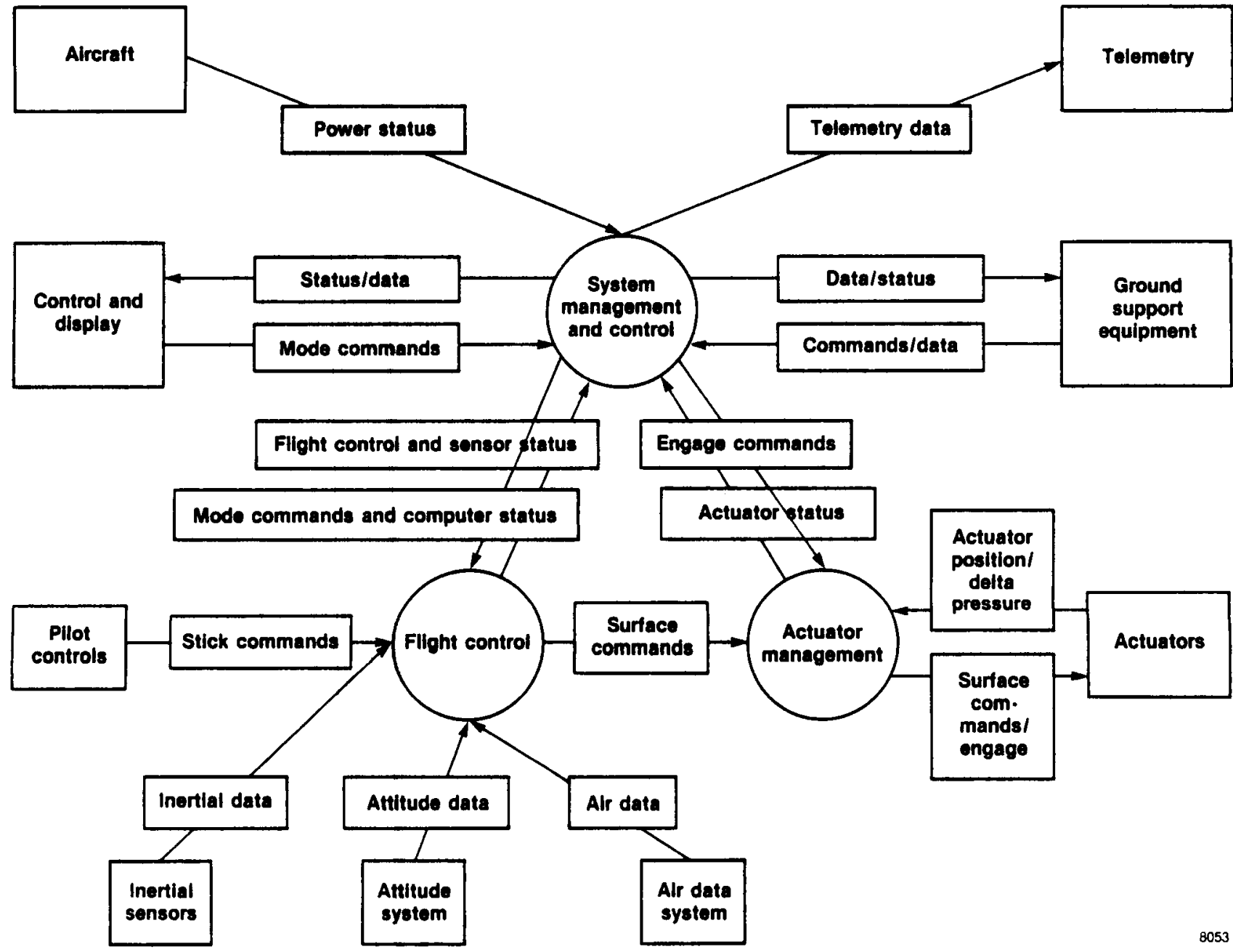

Fig. 10 Top level fight control system diagram. 


\begin{tabular}{|c|c|c|c|}
\hline NASA & \multicolumn{3}{|c|}{ Report Documentation Page } \\
\hline $\begin{array}{l}\text { 1. Report No. } \\
\text { NASA TM-100418 }\end{array}$ & 2. Government Acceselion No. & \multicolumn{2}{|c|}{ 3. Recipient's Cotaloo No. } \\
\hline \multirow{2}{*}{\multicolumn{2}{|c|}{$\begin{array}{l}\text { The NASA Integrated Test Facility and } \\
\text { Its Impact on Flight Research }\end{array}$}} & \multicolumn{2}{|l|}{ 5. Report Date } \\
\hline & & \multicolumn{2}{|c|}{ 6. Porforming Organization Code } \\
\hline \multirow{2}{*}{\multicolumn{2}{|c|}{$\begin{array}{l}\text { 7. Author(s) } \\
\text { D.A. Mackall, M.D. Pickett, L.J. Schilling, and C.A. Wagner }\end{array}$}} & \multicolumn{2}{|c|}{$\begin{array}{l}\text { 8. Performing Organization Report No. } \\
\text { H-1446 }\end{array}$} \\
\hline & & \multirow{2}{*}{\multicolumn{2}{|c|}{$\begin{array}{l}\text { 10. Work Unit No. } \\
\text { RTOP 999-12-08 } \\
\end{array}$}} \\
\hline \multirow{2}{*}{\multicolumn{2}{|c|}{$\begin{array}{l}\text { 9. Porforming Orgenization Name and Addrase } \\
\text { NASA Ames Research Center } \\
\text { Dryden Flight Research Facility } \\
\text { P.O. Box 273, Edwards, CA } 93523-5000\end{array}$}} & & \\
\hline & & \multicolumn{2}{|c|}{ 11. Contract or Grant No. } \\
\hline \multirow{2}{*}{\multicolumn{2}{|c|}{$\begin{array}{l}\text { 12. Sponeoring Ageney Neme and Addraee } \\
\text { National Aeronautics and Space Administration } \\
\text { Washington, DC } 20546\end{array}$}} & \multicolumn{2}{|c|}{$\begin{array}{l}\text { 13. Type of Report and Period Covered } \\
\text { Technical Memorandum }\end{array}$} \\
\hline & & \multicolumn{2}{|c|}{ 14. Sponeoring Agency Code } \\
\hline \multicolumn{4}{|l|}{ 15. Supplementary Notes } \\
\hline \multicolumn{4}{|c|}{ Prepared for presentation at the AIAA 4th Flight Test Conference, May 18-20, 1988, San Diego, California. } \\
\hline \multicolumn{4}{|l|}{ 16. Abatract } \\
\hline \multicolumn{4}{|c|}{$\begin{array}{l}\text { The Integrated Test Facility (ITF), being built at NASA Ames-Dryden Flight Research Facility, will provide } \\
\text { new test capabilities for emerging research aircraft. An overview of the ITF and the challenges being } \\
\text { addressed by this unique facility are outlined in this paper. The current ITF capabilities, being developed } \\
\text { with the X-29 Forward Swept Wing Program, are discussed along with future ITF activities. }\end{array}$} \\
\hline \multicolumn{2}{|c|}{ 17. Koy Words (Sugpeated by Author(s)) } & rent & \\
\hline $\begin{array}{l}\text { Aircraft ground test } \\
\text { Artificial intelligence } \\
\text { Flight test } \\
\text { Guidance and navigation } \\
\text { Simulation }\end{array}$ & & - Unlimited & ject category 09 \\
\hline 19. Socurity Clasalf. (of thie report) & 20. Security Cleadf, lof this pegel & 21. No. of pages & 22. Price \\
\hline Unclassified & Unclassified & 14 & $\mathrm{~A} 02$ \\
\hline
\end{tabular}

*For sale by the National Technical Information Service, Springfield, VA 22161-2171. 